\title{
DEVELOPMENT OF A PATIENT-REPORTED OUTCOME MEASURE (PROM) FOR PITUITARY SURGERY
}

Ali Nikzad Suren ${ }^{1}$, Anna Crown ${ }^{1,2}$ and Sue Jackson ${ }^{3}$.

'Brighton and Sussex Medical School, UK; ${ }^{2}$ Brighton and Sussex University Hospitals NHS Trust, UK; ${ }^{3}$ University of Surrey, UK.

\section{Background}

Healthcare systems worldwide are supplementing conventional clinical outcomes with patient-orientec techniques. Patient-reported outcome measures (PROMs) are standardised validated questionnaires that gauge patients' views on their perception of personal health, quality of care they have received and satisfaction with results. These promising tools utilise HR-QoL ${ }^{1}$ questionnaires but enhance these with specific and customised items allowing for a more detailed and applicable approach. They are currently used in four common surgical procedures across the UK.

Pituitary disorders make up $10-15 \%$ of primary CNS tumours and are mainly treated with transsphenoidal or transcranial surgery. Patients often have a complement of pre- and post-operative symptoms and may suffer from related disorders such as diabetes or depression. This makes pituitary disorders and their treatment feasible targets for PROM testing.

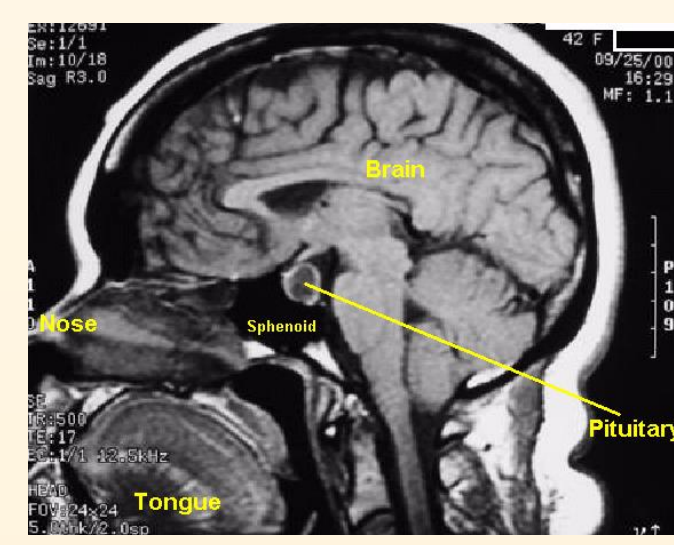

\section{Objectives}

We designed an explorative cross-sectional pilot study to analyse validity and suitability of a PROM questionnaire pack for pituitary surgery.

We then proceeded to test its use for comparing preand post-operative participant samples. Where available, we compared these with population norms.

\section{Methods}

A PROM questionnaire pack composed of 5 sections (Table 1) was created and scrutinised for relevance and acuity using the Fitzgerald et al. ${ }^{2}$ method.

\begin{tabular}{|l|l|l|}
\hline \multicolumn{2}{|l|}{ Table 1: Sections of the pituitary PROM. } \\
\hline A & General health update & $\begin{array}{l}\text { Makes enquiries about pituitary } \\
\text { patients' symptoms and any } \\
\text { comorbidities }\end{array}$ \\
\hline B & Personal report & $\begin{array}{l}\text { Semi-qualitative questionnaire } \\
\text { around psychosocial well-being } \\
\text { and patients' ability to cope }\end{array}$ \\
\hline C & SF36 Health Survey & $\begin{array}{l}\text { Validated questionnaire on } \\
\text { functional and mental well-being }\end{array}$ \\
\hline D & $\begin{array}{l}\text { Hospital Anxiety \& } \\
\text { Depression Scale } \\
\text { (HADS) }^{4}\end{array}$ & $\begin{array}{l}\text { Enquiries about symptoms of } \\
\text { anxiety and depression }\end{array}$ \\
\hline E & $\begin{array}{l}\text { EuroQoL Group 5 } \\
\text { Dimensions (EQ-5D) }\end{array}$ & $\begin{array}{l}\text { Concise and relatively new; } \\
\text { similar questions to SF36 but } \\
\text { much shorter }\end{array}$ \\
\hline
\end{tabular}

Sections A and B were specifically tailored to pituitary patients using data obtained from previous studies ${ }^{6}$.

Ethical approval was obtained from NHS Research Authority (NRES Committee Hampstead, London, UK) and Brighton and Sussex University Hospitals NHS Trrust Research and Development Committee.

All patients attending the combined pituitary surgica MDT clinic at Hurstwood Park Neurological Centre Haywards Heath, UK from December 2013 to April 2014 were invited to take part in the study (Figure 1). Patients were informed of the study prior to attending clinic and consented using standard consent forms.

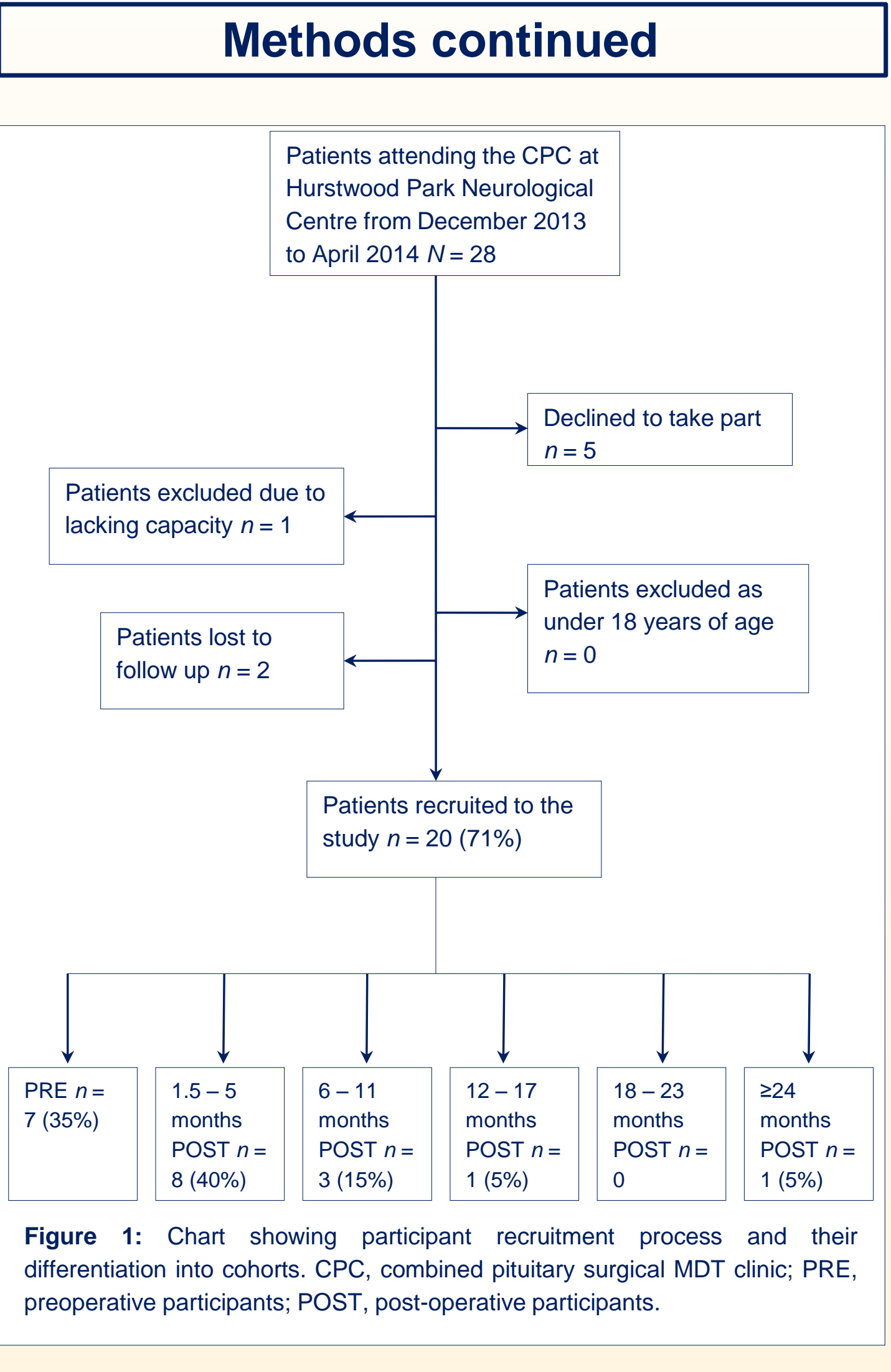

We also collected data for conventional clinical outcomes for all participants in parallel. This included type of surgery, any complications and type of pituitary tumour.

\section{Results}

Participant data was collected using paper questionnaire packs completed within clinic at a private area. Majority of participants were able to complete the PROM questionnaire within timeframe of 20 minutes. Patient demographic data is described below. Many participants (45\%) at least had 2 comorbidities such as hypertension, diabetes or hypothyroidism. Participants did not find questions within the PROM distressing and found the questionnaires self-explanatory.
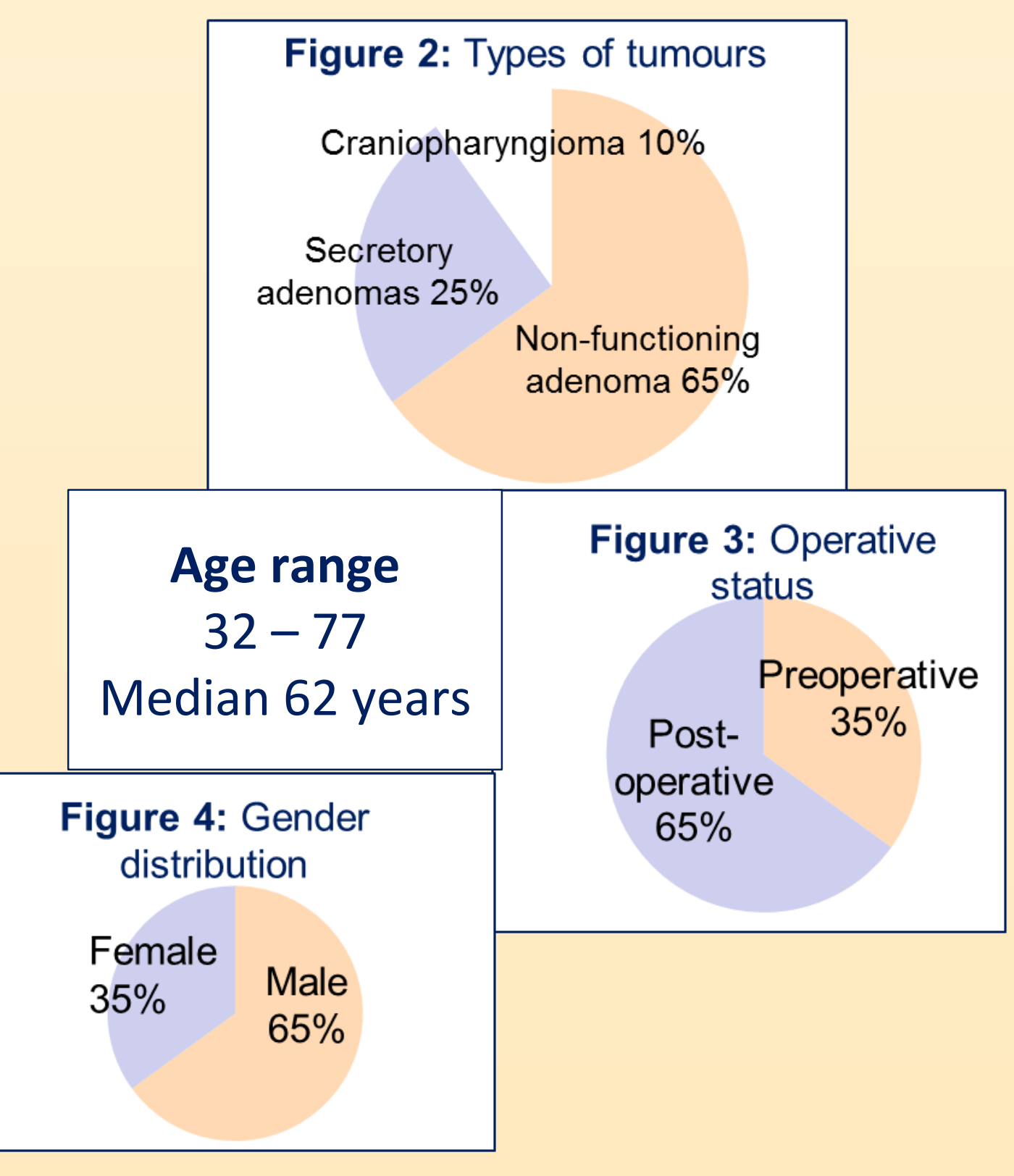

Nearly all data obtained in the study indicated a worse biopsychosocial profile in post-operative participants. This was evident in data from section A general health update (Figure 5) and was repeated across the study.

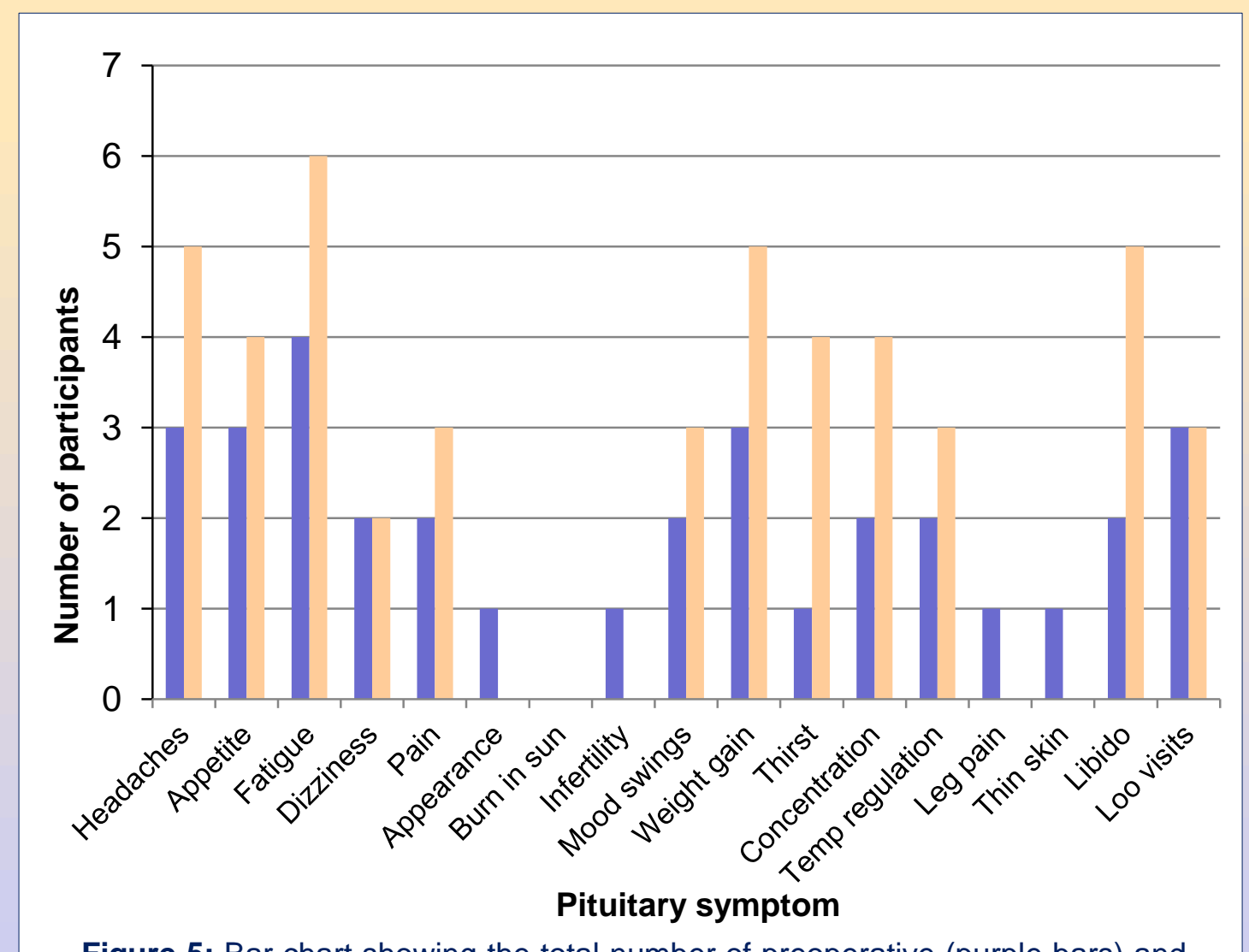

Figure 5: Bar chart showing the total number of preoperative (purple bars) and post-operative (orange bars) participants experiencing each of the $\mathrm{p}$
relevant symptoms, inferred from the pituitary distress thermometer study.

\section{Results continued}

Data from section B personal report revealed pituitary patients found their pituitary disorder had little impact on their global quality of life and they were generally able to cope well. This was interesting compared to results below.

Where available data from study was compared to population norms. SF36 data from this study sample indicated pituitary patients have a worse profile than general population although notably social function was better (Figure 6).

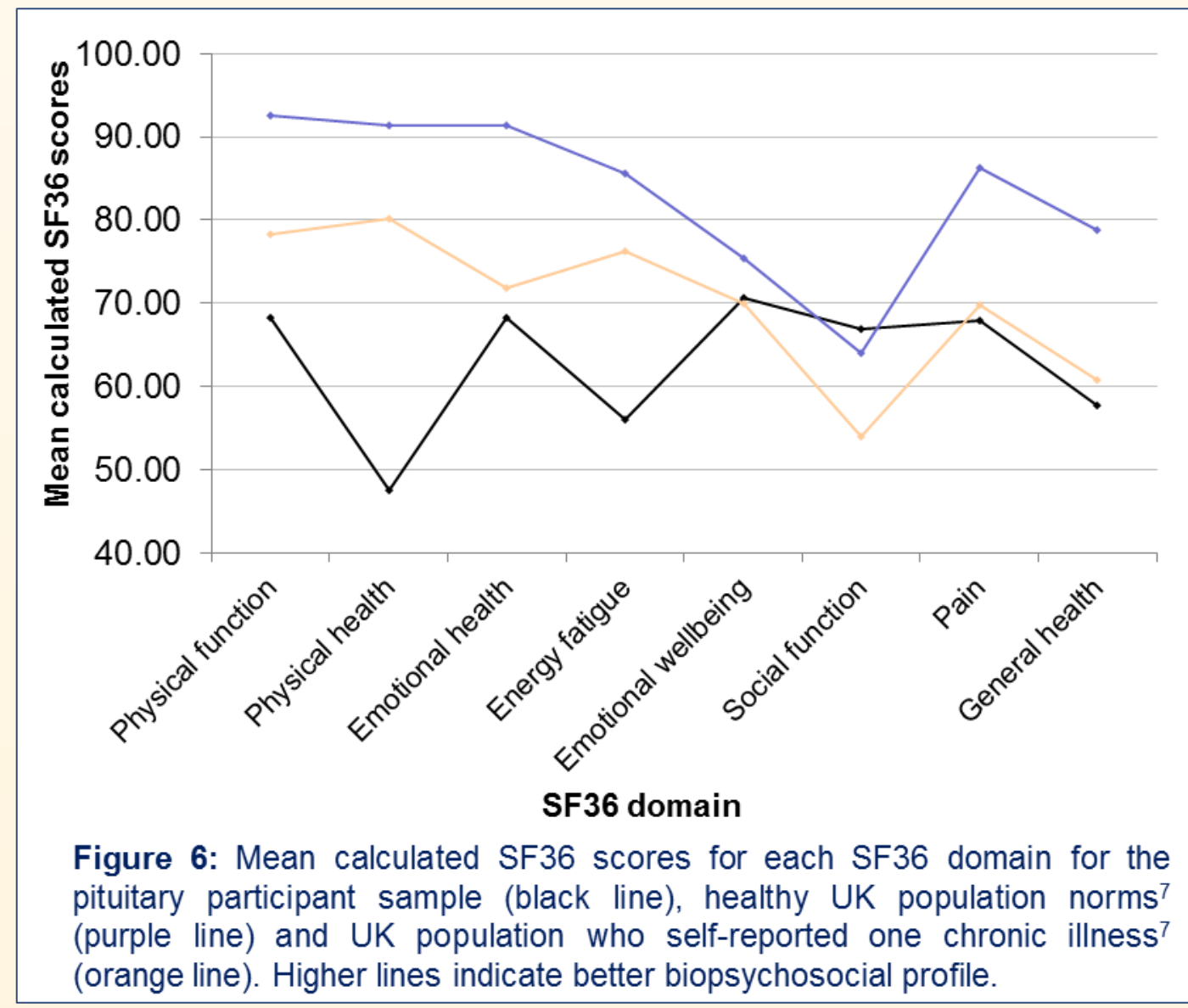

HADS data suggested equivocal anxiety and but greater depression in participant sample compared to population norms (Figure 7).

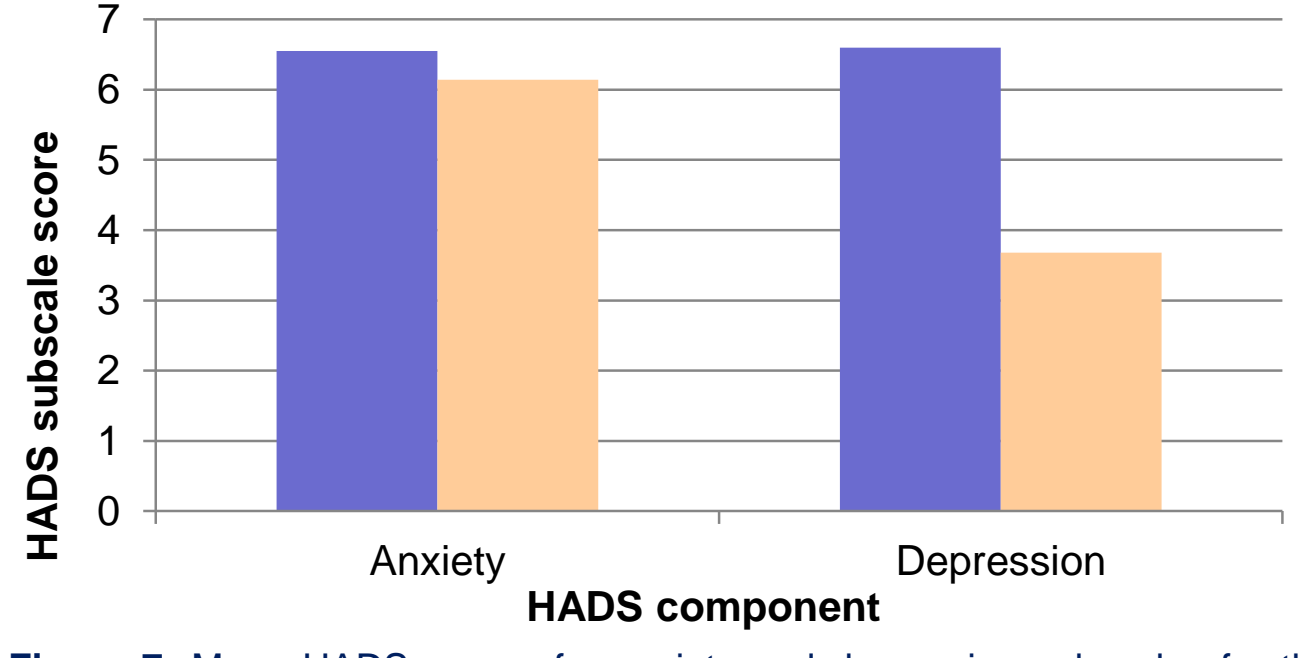

Figure 7: Mean HADS scores for anxiety and depression subscales for the Higher scores correlate with more anxious or depressive symm (oratse bur

Overall EQ-5D score for participant sample was 0.91 from a maximum of 1 revealing a relatively preserved quality of life

\section{Conclusions}

This study has shown promise in PROMs for pituitary disorders and surgery. The study results illustrate that PROMs in this field can be informative and useful for inspecting pituitary patients' biopsychosocial profile and its determinants. Additionally, several themes were discovered regarding PROM design and evaluation of results which will be useful in future studies to extend the validity and reliability of the questionnaires.

It is essential that this research is followed to determine the appropriate time for administration of PROMs following pituitary surgery to post-operative patients as results suggest responses may be considerably different depending on this time factor, along with results indicating a better biopsychosocial profile in preoperative sample.

Nonetheless, portions of data indicate that pituitary surgery does not have a significant adverse effect on patients' quality of life and that other factors should also be considered. This finding requires further exploration as well.

References

1. Health-related quality of life

2. Fitzpatrick R, Davey C, Buxton MJ, Jones DR. Health technol assess. 1998;2(14):i-iv, 1-74.

3. Ware JE, Jr., Sherbourne CD. Med care. 1992;30(6):473-83.

4. Zigmond AS, Snaith RP. Acta psychiatr Scand 1983;67(6):361-70.

5. EuroQol Group. Health policy. 1990;16(3):199-208.

6. Bowes P. [Unpublished Dissertation] 2013.

7. Jenkinson C, Coulter A, Wright L. BMJ. 1993;306(6890):1437-

8. Crawford JR, Henry JD, Crombie C, Taylor EP. Brit j clin psychol. 2001:40(Pt 4):429-34. 